\title{
INTRATHECAL AND INTRAMUSCULAR AMPICILLIN IN THE TREATMENT OF HAEMOPHILUS INFLUENZA MENINGITIS IN INFANTS
}

\author{
J. D. PickuP, M.D., D.C.H. \\ Consultant Paediatrician
}

\author{
P. K. A. McWilliam, M.B., Ch.B., D.C.H. \\ Clinical Assistant in Paediatrics
}

Pontefract General Infirmary, Yorkshire.

THE DEVELOPMENT of ampicillin and its effectiveness against Gram-negative organisms has led to its use in the treatment of meningitis due to Haemophilus influenzae with encouraging results (Ivler, Thrupp, Leedom, Wehrle and Portnoy, 1963; Thrupp, Leedom, Ivler, Wehrle, Brown, Mathios and Portnoy, 1964; Pickup and Mathur, 1964).

Ampicillin for intrathecal injection is now available in this country and we report clinical details of four infants aged between eight and fifteen months, suffering from Haemophilus influenzae meningitis, who were treated with combined intrathecal and intramuscular ampicillin.

\section{Materials and Methods}

Four cases were admitted to this hospital during the winter of 1964-65. This investigation was planned to run pari passu with treatment, thus obviating the need for additional lumbar punctures. When lumbar puncture was performed some CSF was taken off before the intrathecal injection and stored in a deep freeze before being sent for ampicillin assay. The ampicillin concentrations given below represent the drug concentration in the CSF twentyfour hours after the intrathecal dose, unless otherwise stated.

\section{Method of Assay}

The ampicillin concentrations in the specimens of CSF were determined by microbiological assay using an agar diffusion method with Sarcina lutea as test organism (Knudsen, Rolinson and Stevens, 1961). The diluent used for the test specimens and for the standard solutions was $\mathrm{M} / 20$ phosphate buffer, pH 7.0.

\section{Duration of Therapy}

In all cases, the duration of therapy was determined by clinical and CSF findings. No rigid or pre-arranged criteria were used.

\section{Case Reports}

Case No. 1. Male, weighing 22 lbs., aged fifteen months. Admitted with a week's history of irritability, anorexia, loss of weight and constipation. Neck stiffness and one generalised convulsion on the day of admission. Therapy with oral penicillin had been given for three days prior to admission.

On examination, he was alert but fretful. He had signs of an upper respiratory infection and definite neck stiffness.
CSF : $-5,500$ cells /cu. mm., polys $90 \%$; Haemophilus influenzae grown on culture.

Treatment: Intramuscular ampicillin $125 \mathrm{mg}$. six hourly for 21 days. Intrathecal ampicillin $5 \mathrm{mg}$. daily for 3 days and then after a lapse of 2 days for a further 8 days (see below).

\section{CSF Ampicillin Assay}

1. 12 hours after the commencement of intramuscular therapy $-0.5 \mu \mathrm{g}$. ampicillin $/ \mathrm{ml}$.

2. 24 hours after the first intrathecal dose of $5 \mathrm{mg}$. of ampicillin- $0.3 \mu \mathrm{g} . / \mathrm{ml}$.

3. 24 hours after the second intrathecal dose of $5 \mathrm{mg}$. ampicillin $-0.25 \mu \mathrm{g} . / \mathrm{ml}$.

Progress: Improvement occurred until the fifth day when the clinical condition relapsed, with fever, vomiting and the recurrence of neck stiffness. Lumbar puncture: CSF cell count of $9,000 \mathrm{cu}$. mm., $99 \%$ polys. Haemophilus influenzae identified in CSF.

Intrathecal therapy was recommenced and two further CSF ampicillin assays were done, as follows:

24 hours after the fourth intrathecal dose of $5 \mathrm{mg}$. ampicillin- $0.15 \mu \mathrm{g} . / \mathrm{ml}$.

24 hours after the fifth intrathecal dose of $5 \mathrm{mg}$. ampicillin- $<0.1 \mu \mathrm{g} . / \mathrm{ml}$.

Uninterrupted clinical recovery then took place. Child apparently progressing well on out-patient follow up.

Case No. 2. Female, weighing 14 lbs., aged eight months. Had a week's history of rhinorrhoea, vomiting and fever. Oral penicillin administered for two days prior to admission-was not retained because of the vomiting.

On examination, a descending upper respiratory infection with neck stiffness was noted. CSF : 2,500 cells $/$ cu. mm., $88 \%$ polys. Haemophilus inflenzae identified.

Treatment: Intramuscular ampicillin $125 \mathrm{mg}$. six hourly for 14 days. Intrathecal ampicillin $5 \mathrm{mg}$. daily for 9 days.

CSF Ampicillin Assays

1. 12 hours after the commencement of intramuscular ampicillin $-0.38 \mu \mathrm{g} . / \mathrm{ml}$.

2. 24 hours after the first intrathecal dose of $5 \mathrm{mg}$. ampicillin- $0.88 \mu \mathrm{g} . / \mathrm{ml}$.

3. 24 hours after the second intrathecal dose of $5 \mathrm{mg}$. ampicillin- $0.23 \mu \mathrm{g} . / \mathrm{ml}$.

4. 24 hours after the third intrathecal dose of $5 \mathrm{mg}$. ampicillin- $0.34 \mu \mathrm{g} . / \mathrm{ml}$.

5. 24 hours after the fourth intrathecal dose of $5 \mathrm{mg}$. ampicillin-1.5 $\mu \mathrm{g} . / \mathrm{ml}$.

Progress: This baby made a progressive, uneventful recovery and was thought to be normal on outpatient follow up. Two-and-a-half months after 
discharge, however, she was re-admitted with acute bronchitis but there were no meningeal signs and the CSF was found to be normal.

Case No. 3. Female, weighing 22 lbs. aged one year. Admitted with a four day history of a mild upper respiratory infection. On the day of admission she was drowsy and had vomited twice.

On examination, there was a descending upper respiratory infection, neck stiffness and a Kernig's sign. OSF- 6,500 cells/cu. mm., polys $90 \%$. Initially this child was thought to be suffering from meningococcal meningitis and therapy was commenced with intramuscular penicillin $G$ and oral sulphadimidine. Later on the day of admission, because of clinical deterioration, a further lumbar puncture was performed and Haemophilus influenza was cultured from the CSF.

Treatment: Treatment with ampicillin was as follows:

An immediate dose of $10 \mathrm{mg}$. was given intrathecally, and on each of the following four days $5 \mathrm{mg}$. intrathecally. The drug was given intramuscularly in a dosage of $125 \mathrm{mg}$. six hourly. Owing to the child's condition oral sulphadimidine was continued for nine days and intramuscular penicillin $G$ was continued for six days.

\section{CSF Assays}

1. $12 \frac{1}{2}$ hours after the first dose of $10 \mathrm{mg}$. intrathecal ampicillin- $0.75 \mu \mathrm{g}$. antibiotic $/ \mathrm{ml}$.

2. 24 hours after the second dose of $5 \mathrm{mg}$. intrathecal ampicillin- $0.6 \mu \mathrm{g}$. antibiotic $/ \mathrm{ml}$.

3. 24 hours after the third dose of $5 \mathrm{mg}$. intrathecal ampicillin- $0.9 \mu \mathrm{g}$. antibiotic/ml.

Sulphonamide activity was eliminated with paraaminobenzoic acid. It was not possible to differentiate between pencillin $G$ and ampicillin so that the assay represents total antibiotic content.

Progress: The child made good progress and was developing normally at out-patient follow up.

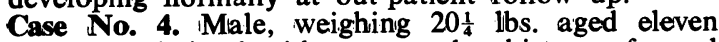
months. Admitted with a seven-day history of nasal discharge and slight cough. Irritability, fever and vomiting were noted three days prior to admission. On examination, there were signs of an upper respiratory infection and slight neck stiffness. CSF : $1 ! 1,500$ cells/cu. mm., polys $90 \%$ Haemophilus influenzae noted in CSF.

Treatment: It was decided (see below) to treat this baby with larger doses of intrathecal and intramuscular ampicillin, i.e., Intrathecal ampicillin $10 \mathrm{mg}$. daily for four days. Intramuscular ampicillin $500 \mathrm{mg}$. stat and $250 \mathrm{mg}$. six hourly for fourteen days.

CSF Assays

1. 12 hours after $500 \mathrm{mg}$. ampicillin intramuscularly $-2.8 \mu \mathrm{g} . / \mathrm{ml}$.
2. 24 hours after first dose of $10 \mathrm{mg}$. «mpicillin intrathecally $\rightarrow 13.8 \mu \mathrm{g} . / \mathrm{ml}$.

3. 24 hours after second dose of $10 \mathrm{mg}$. ampicillin intrathecally $-1.4 \mu \mathrm{g}$. $/ \mathrm{ml}$.

4. 24 hours after third dose of $10 \mathrm{mg}$. ampicillin intra thecally $-0.4 \mu \mathrm{g} . / \mathrm{ml}$.

5. 24 hours after fourth dose of $10 \mathrm{mg}$. ampicillin intrathecally $-5.2 \mu \mathrm{g} . / \mathrm{ml}$.

Progress: The child made good progress and was thought to be developing normally on follow up.

\section{Discussion}

The ampicillin levels in the CSF samples from our cases showed wide variation. Such variation was described by Ivler and Thrupp and their colleagues in their cases treated by ampicillin and they suggested that the minimum inhibitory concentration against Haemophilus influenzae is $0.4 \mu \mathrm{g} . / \mathrm{ml}$. This level was consistently maintained in only one of our cases (Case 4), using the higher intramuscular and intrathecal dosages of the drug.

In our opinion amplicillin doses of not less than $10 \mathrm{mg}$. intrathecally daily and $250 \mathrm{mg}$. six hourly intramuscularly are required for the treatment of this condition in infants.

We thank Mr. R. Sutherland B.Sc., of Beecham Research Laboratories for doing the assays, Dr. E. T. Knudsen of Beecham Research Laboratories for his help and advice, Dr. E. L. Simons for his bacterial reports and Mr. S. G. Rowley, F.P.S., for his assistance with the transport of the specimens.

\section{REFERENCES}

IVler, D., ThrupP, L. D., LeEDOM, J. M., Wehrle, P. F., and PORTNOY, B. (1963): Antimicrobial Agents and Chemotherapy-p. 335. American Society of Microbiology.

KNUDSEN, E. T., Rolinson, G. N., and Stevens, S. (1961): Absorption and Excretion of Penbritin. Brit. med. J., ii, 198.

PickuP, J. D., and Mathur, B. S. (1964): Haemophilus Influenzae Meningitis Treated with Parenteral and Intrathecal Penbritin, Postgrad. med. J., 40, 204.

ThrupP, L. D., Leedom, J. M., IVler, D., WeHRLE, P. F., Brown, J. F., Mathios, A. W., and Portnoy, B. (1964): Haemophilus Influenzae Meningitis. A Controlled Study of Treatment with Ampicillin., Postgrad. med. J., 40, Suppl. p. 119. 